\title{
A TERMOGRAFIA COMO A FORMA MAIS SIMPLES E RÁPIDA NA RESOLUÇÃO DE
}

\section{PROBLEMAS ELÉTRICOS!}

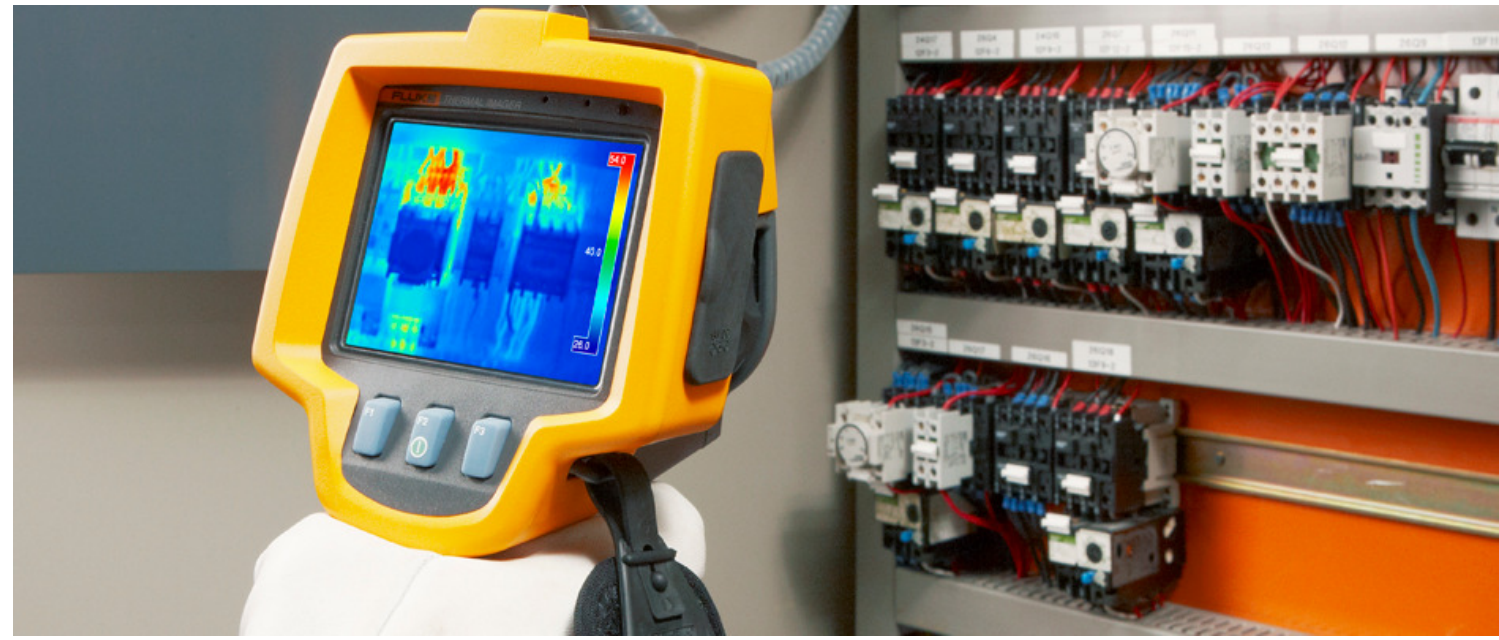

\section{Deteção de desequilíbrios e sobrecargas}

As imagens térmicas são uma forma simples de identificar diferenças de temperatura em circuitos de sistemas trifásicos, comparando com a sua operação em condições normais. Inspecionando o gradiente térmico das três fases juntas, podemos rapidamente detetar anomalias, numa das fases, devido a desequilíbrios ou sobrecargas.

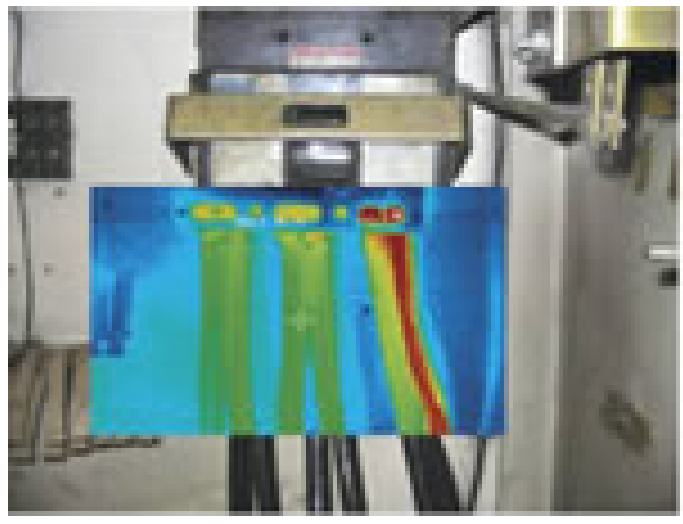

O desequilíbrio pode ser provocado por diferentes causas:

- problema na entrega de energia

- baixa tensão numa das fases

- um defeito de isolamento em cablagem

- mau dimensionamento de cargas na instalação elétrica.
Até um baixo desequilíbrio de tensão pode causar deterioramento nas conexões, reduzindo a tensão fornecida, enquanto motores e outras cargas irão desenhar correntes excessivas, entregando um binário reduzido (com o respetivo stress mecânico), e entrando em falha.

Um desequilíbrio severo pode danificar um fusível, reduzindo as operações para uma simples fase. Entretanto, o desequilíbrio de corrente irá regressar no neutro, provocando caminho fácil para um pico de potência.

Na prática, é muito difícil equilibrar as tensões nas três fases. Para ajudar, os técnicos eletrotécnicos determinam níveis aceitáveis de desequilíbrio para diversos equipamentos, conforme as respetivas normas em vigor. Estas serão linhas de orientação úteis para comparação durante a manutenção e deteção de problemas.

\section{O que verificar com a Câmara termográfica?}

Capture imagens térmicas de todos os quadros elétricos e outras conexões de cargas elevadas, tal como barramentos de entrada do Quadro Geral de Baixa Tensão.

Onde descobrir elevadas temperaturas, siga o circuito e examine as cargas associadas. 
Faça uma verificação nos quadros elétricos e conexões, retirando as coberturas dos mesmos.

Preferencialmente, deve verificar equipamentos elétricos quando estes estão a $40 \%$ da carga nominal. Desta forma, pode realizar as medidas de uma forma correta e comparar com as condições normais de funcionamento.

Carga igual deve possuir temperatura igual. Numa situação de desequilíbrio de cargas, as fases com maior carga aparecerão mais quentes, devido ao calor gerado pela resistência. No entanto, uma carga desequilibrada, uma sobrecarga, uma má conexão ou desequilíbrio harmónico, podem causar um efeito semelhante. Medir a carga é importante para diagnosticar o problema.

É procedimento normal criar uma regular de inspeção, que inclua os pontos de referência da instalação.

Use o software fornecido com a sua Fluke Ti25 para guardar as imagens que capturar no seu computador, de forma a verificar modificações ao longo do tempo. Desta forma, terá uma base de trabalho para comparar futuras anomalias ou reparações realizadas.

\section{Como identificar uma anomalia?}

As reparações devem ter em conta em primeiro lugar a segurança, isto é, se as condições do equipamento colocam a segurança em risco, e em segundo lugar o aspeto crítico do equipamento e a extensão do aumento de temperatura.

As linhas da NETA (International Electrical Testing Association) apontam para uma ação imediata sempre que a diferença de temperatura (DT) entre componentes elétricos semelhantes exceda os $15 \circ \mathrm{C}$, ou quando o DT entre o componente elétrico e temperatura ambiente do ar exceda os $40^{\circ} \mathrm{C}$.

Quando a imagem térmica mostrar a totalidade do condutor mais quente que outros componentes, numa parte do circuito, o condutor pode estar subdimensionado ou em sobrecarga.
Verifique se o condutor foi corretamente dimensionado para a carga que o percorre. Use para este procedimento uma pinça de corrente ou um analisador de redes, para verificar o diagrama vetorial e carga existente.

Na parte da tensão, o valor entre o neutro e a terra diz-lhe quando o seu sistema está sobrecarregado e ajuda-o a determinar a corrente harmónica. Tensões entre neutro e terra superiores a $3 \%$ necessitam de uma investigação mais detalhada. As cargas mudam, e uma fase pode rapidamente baixar $5 \%$, se uma elevada carga monofásica entrar em serviço.

A solução mais comum para uma sobrecarga é a redistribuição da carga pelos circuitos ou a supervisão da carga durante a entrada em serviço de um determinado processo. Usando o software SmartView (fornecido com as câmaras Fluke), cada problema detetado pela Fluke Ti25 ou Ti10 pode ser documentado num relatório pré-formatado, com a imagem térmica e visível do problema detetado. Esta é a melhor forma de comunicar problemas e sugerir reparações.

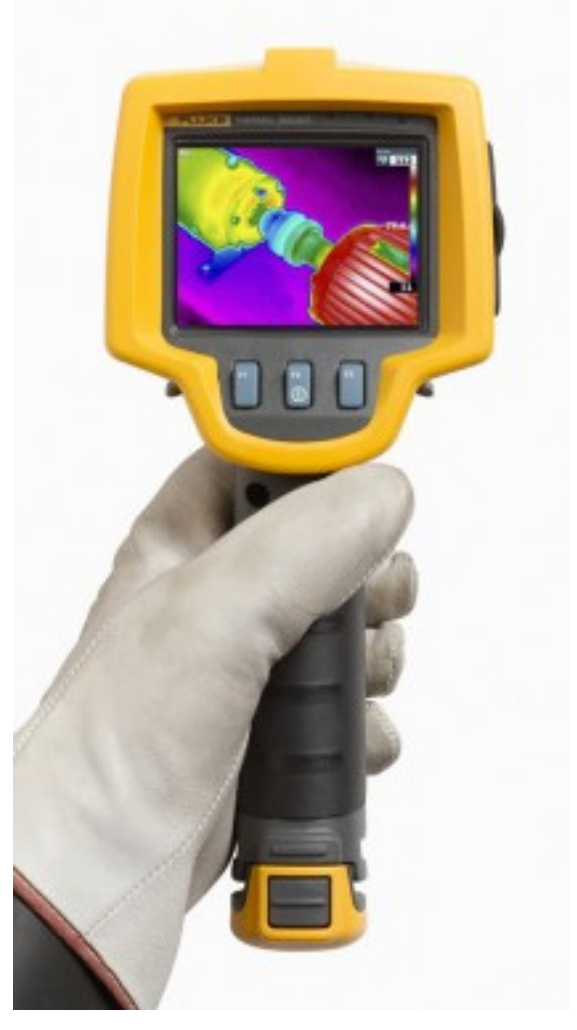

